We have no reason, however, to suspect that there was any sex difference in this respect, so that our comparisons between men and women were unlikely to have been seriously affected by this source of error.

The fact that $32 \%$ of the men and $45 \%$ of the women smokers thought that they could change permanently to a low-nicotine brand suggests real scope for health educationists in encouraging them to do so.

We thank the following general practitioners for co-ordinating their partners and allowing us to study their patients: Dr I F Crabbe, Dr Elisabeth Horder, Dr M A Newland, and Dr R H Burton. We also thank R Iyer for statistical help and Jean Crutch for secretarial work. Our colleagues J R Eiser, $M$ Jarvis, $M$ Raw, and S R Sutton gave useful advice during the analysis and write-up. Financial support was provided by the Department of Health and Social Security and the Medical Research Council.

\section{References}

1 Cappell PJ. Trends in cigarette smoking in the United Kingdom. Health Trends 1978;10:49-54.

2 Gritz ER. Women and smoking: a realistic appraisal. In : Schwartz JL, ed. Progress in smoking cessation. New York: American Cancer Society, 1978:119-41.

${ }^{3}$ McKennell AC, Thomas RK. Government Social Survey. Adults' and adolescents' smoking habits and attitudes. London: HMSO, 1967.

${ }^{4}$ Russell MAH, Wilson C, Taylor C, Baker CD. Effect of general practitioners' advice against smoking. $B r$ Med F 1979; ii :231-5.

5 Lee PN. Research Paper 1. Statistics of smoking in the United Kingdom. 7th ed. London: Tobacco Research Council, 1976.

${ }^{6}$ Russell MAH. Cigarette smoking: natural history of a dependence disorder. Br 7 Med Psychol 1971;41:1-16.

7 Todd GF. Research Paper 1. Statistics of smoking in the United Kingdom. 6th ed. London: Tobacco Research Council, 1972.

(Accepted 2 April 1980)

\title{
Intermittent treatment of duodenal ulcer with cimetidine
}

\author{
KARNA DEV BARDHAN
}

\section{Summary and conclusions}

Intermittent treatment with short courses of cimetidine given only when symptoms recurred was assessed in patients with duodenal ulcer as an alternative to maintenance treatment. Their progress was followed up for up to 22 months. Gastroscopy was carried out in most attacks to confirm recurrence of the ulcer and subsequent healing. Out of 125 patients treated, 83 relapsed, of whom 21 defaulted. After retreatment 36 patients relapsed again. The pattern of relapse and remission for the group as a whole was similar after both courses of treatment, indicating an unchanged natural history. Nevertheless, wide variation occurred in individual patients, so that the pattern of relapse could not be predicted by the duration of the initial remission.

Most patients had one or two or rarely three symptomatic relapses a year, which were rapidly treated successfully with cimetidine. Therefore, unless the necessity for long-term maintenance treatment is established, intermittent treatment provides an adequate alternative in most patients with duodenal ulcer.

\section{Introduction}

After initial treatment with cimetidine to heal duodenal ulcer maintenance treatment at a lower dose is often recommended to prevent recurrence. Though the treatment is generally effective, no data are available on the results beyond a year. ${ }^{2}$ Several unanswered questions remain: Is such treatment effective over longer periods? Do all patients require it, and if not how should patients be selected ? How long should treatment be continued ? Will it remain safe? Because these questions have not been answered I have used an alternative method of treatmentnamely, giving cimetidine only when troublesome symptoms

District General Hospital, Rotherham S60 2UD

KARNA DEV BARDHAN, DPHIL, MRCP, consultant physician recur. Though this method is commonly used in hospitals and general practice, its outcome has not been assessed. I therefore report here on the use of intermittent treatment in 125 patients.

\section{Patients and methods}

Patients with duodenal ulcer were treated with cimetidine $1 \mathrm{~g}$ daily until the ulcer had healed; ulceration and healing were confirmed by endoscopy. The drug was then stopped. If minor symptoms such as slight heartburn or upper abdominal discomfort continued or recurred the patients were advised to use small amounts of antacids. If, however, their symptoms became troublesome they came back to see me and after assessment received a second course of cimetidine. This was repeated for a third time if a further relapse occurred. In most patients cimetidine for one to two months produced healing. During most relapses endoscopy was repeated to confirm both ulceration and healing before the cimetidine was begun again and stopped. In 10 episodes, however, this was not possible. These patients are nevertheless included for analysis because they had a recurrence of typical symptoms that almost invariably indicated reulceration. ${ }^{3}$

The patients' progress was followed up for up to 22 months, after which time those who had not recently had a relapse were recalled for interview. The pattern of relapse and remission was examined. The remission period was arbitrarily taken to be the period when the patients were not taking cimetidine.

\section{Results}

One hundred and twenty-five patients were treated until the ulcer healed. During the next 22 months 83 patients relapsed (fig 1 ). After six months 48 patients (38\%) had relapsed including five $(4 \%)$ in less than one month, but 53 patients $(42 \%)$ were in clinical remission for over one year. Of the patients who relapsed, 21 defaulted. The remaining 62 patients were retreated, but 36 relapsed again. Of these, $29(47 \%)$ had relapsed by six months including five $(8 \%)$ in less than one month, but $29(47 \%)$ were asymptomatic for over a year (fig 2). The pattern of the second relapse was similar to that of the first.

From these data the probability that a patient would remain in remission after treatment with cimetidine was calculated by lifetime analysis (fig 3). The results after one and two short courses of cimetidine are similar, indicating that the natural history of the disease is unchanged. Figure 3 also shows that the chances of staying 
in remission fall sharply for the first six months; thereafter they fall less steeply. Thus at one month or less the cumulative probability of relapse is $9 \%$; the corresponding figures for three and six months are $23 \%$ and $40 \%$. Conversely, $60 \%$ of patients are likely to be in remission at six months, $48 \%$ at nine months, and $38 \%$ at 12 months.

Though the pattern of relapse and remission for the patients as a whole repeated itself, this was not the case for individual patients.

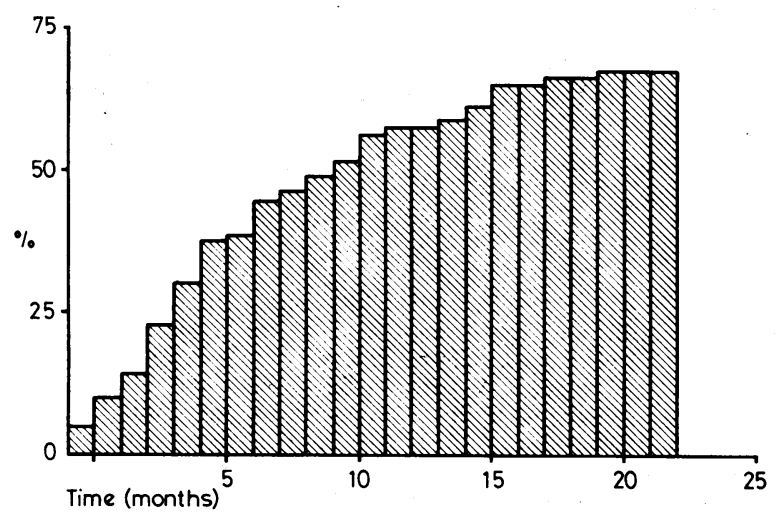

FIG 1-Cumulative relapse rate after first course of cimetidine in 125 patients ( 83 patients had relapsed after 22 months). The first bar shows the proportion of patients who relapsed in less than one month after stopping the drug (4\%); the succeeding bars show the cumulative relapse rate at the end of each month of follow-up. By three, six, and 12 months $22 \%, 38 \%$, and $58 \%$ respectively had relapsed; 53 patients $(42 \%)$ were in remission for over a year.

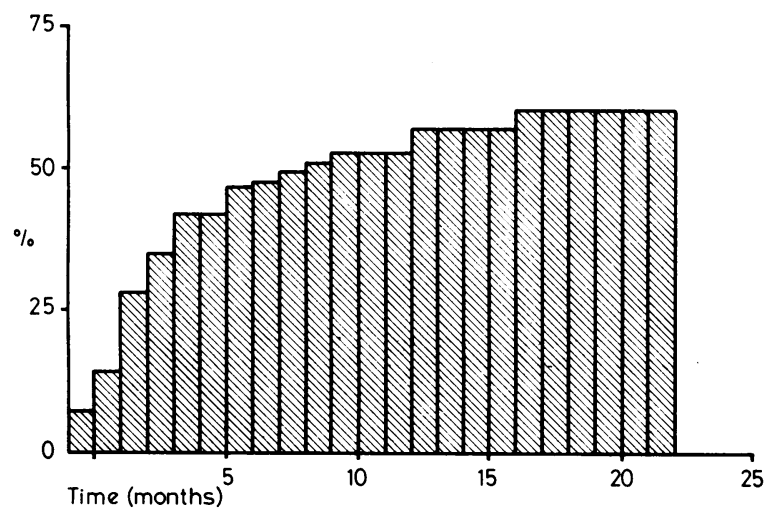

FIG 2-Cumulative relapse rate after second course of cimetidine. in 62 patients ( 36 patients had relapsed after 22 months). The first bar shows the proportion of patients who relapsed in less than one month after stopping the drug $(8 \%)$; the succeeding bars show the cumulative relapse at the end of each month of follow-up. By three, six, and 12 months $36 \%, 47 \%$, and $53 \%$ respectively had relapsed; 29 patients $(47 \%)$ were in remission for over a year.

Figure 4 shows the relation between the durations of the first and second remission periods in the 36 patients who relapsed twice after the initial course of cimetidine. While some repeatedly relapsed shortly after cimetidine was withdrawn, in others there was no correlation. Therefore, in individual patients the long-term pattern of relapse cannot be accurately predicted by short-term observations.

One complication occurred. A frail 76-year-old man had recurring mild pain for two weeks, and reulceration was confirmed. Ironically, while he was going to the pharmacy to collect some cimetidine his ulcer perforated. This was repaired, but five days later he died of bronchopneumonia.

\section{Discussion}

From my data I would expect that out of 100 patients observed for a year, only seven would have three or more major symptomatic attacks while 20 would have two attacks; in contrast, 37 would have only one attack and 36 would have none. As a short course of cimetidine rapidly relieves symptoms and accelerates healing in most cases, and since most patients only rarely relapse, the question arises whether these patients need continuous prophylactic treatment.

The main source of error in this study is the difficulty in measuring the remission period accurately; symptoms generally develop gradually and may have been present for weeks before the patients refer themselves back. Appreciable error is unlikely to have been made, however, since the pattern of relapse is similar to that seen in patients receiving placebo in double-blind studies of maintenance treatment ${ }^{2-5}$ and in patients followed up without further treatment. ${ }^{\circ}$ ?

About one-fifth of patients are unsuitable for intermittent treatment-namely, those who in the past have repeatedly started their attacks with haemorrhage or perforation or have abruptly developed severe pain. In most cases symptoms develop gradually and there is enough time to intervene. If such warning symptoms are absent this form of treatment cannot be used.

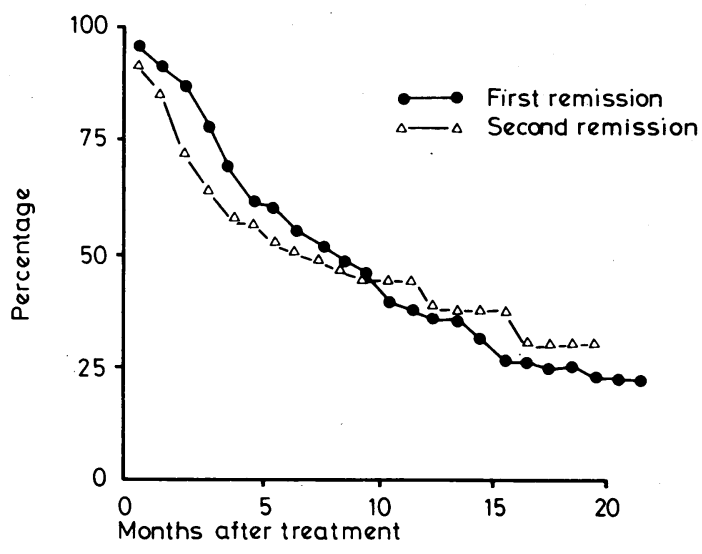

FIG 3-Probability of staying in remission after one and two short courses of cimetidine.

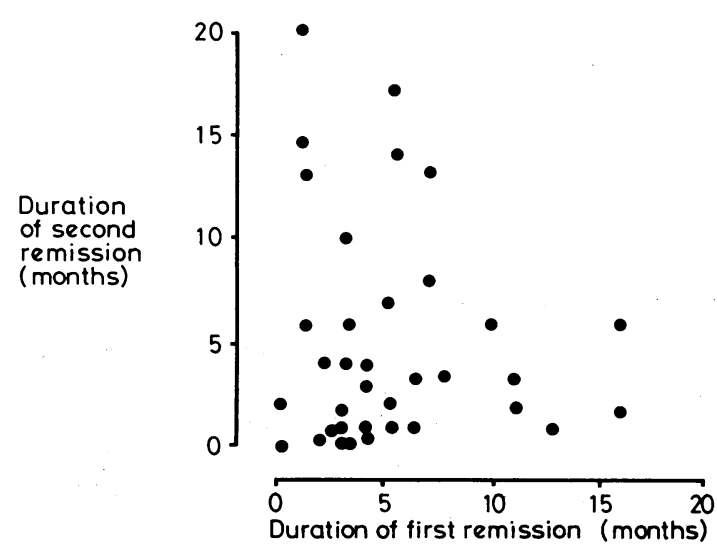

FIG 4-Correlation between durations of first and second remission periods in 36 patients.

There is also a small but unavoidable risk of haemorrhage or perforation with ulcer recurrence, which might have serious consequences in the elderly or in those who also have other severe disease, such as cardiorespiratory problems; such patients are therefore not suitable for intermittent treatment.

Despite these limitations, intermittent treatment has advantages. Firstly, it is simple: once duodenal ulcer has been confirmed treatment may be managed without further endoscopy or radiology. Recurrence of typical symptoms generally indicates reulceration, and a one- to two-month course of cimetidine will heal the ulcer in most cases. Investigations may be reserved for the few patients with atypical symptoms or when symptoms persist despite treatment. Therefore such treatment 
may be used in general practice, where most patients with ulcers are seen.

Secondly, intermittent treatment is more economical: less drug is required than for maintenance treatment. Assuming that on average a six-week course of cimetidine $1 \mathrm{~g}$ daily is required to heal a duodenal ulcer and provided that there are no contraindications, for 100 patients treated intermittently during one year about 200 courses would be required. The trade price of cimetidine is $£ 13.22$ per hundred 200 -mg tablets, excluding dispensing fees:; based on this figure the drug cost for such treatment is therefore about $£ 5500$. (I have excluded any costs incurred owing to a delay in restarting treatment, leading to worsening of symptoms and loss of time at work, or to the occurrence of haemorrhage or perforation.) In contrast, if after initial treatment these patients are put on prophylactic low-dose maintenance treatment with cimetidine $400 \mathrm{mg}$ nightly for a year, and allowing for $13 \%$ to have a symptomatic relapse requiring retreatment with full doses of cimetidine, the drug cost is about $£ 12600$. Therefore, though maintenance treatment (or surgery) is the only suitable method of treating several patients, in most cases intermittent treatment provides a cheaper method of obtaining satisfactory results.

Thirdly, patients who rapidly and repeatedly relapse each time cimetidine is withdrawn are easily recognised; they may confidently be selected for maintenance treatment or surgery.

In conclusion, given the uncertainties of long-term low-dose maintenance treatment with cimetidine, intermittent treatment provides a reasonable alternative for the longer-term treatment of most patients.

This study would not have been possible without help from many people. Mrs Denise Grove, my former secretary, helped to interview patients and develop the open referral system for gastroscopy, which was ably continued by Mrs Janice Law, who also typed the paper, and Mrs Stephanie Hardy. Sister J Brooksbank, her day-ward staff, Nurse A Malia, and the endoscopy nurses coped with ever-increasing numbers of patients. The consultant physicians and surgeons and general practitioners continued to refer patients. The patients continued to attend largely to support research. Drs C D Holdsworth (consultant physician, Royal Hallamshire Hospital, Sheffield), A M Cantor, and A R Haste (consultant physicians, Rotherham) made many helpful comments. Mr A Tunstill and his colleagues (medical illustrations, Royal Hallamshire Hospital) and Mr Barry Farmer (medical illustrations, Rotherham Hospital) provided the illustrations. The Rotherham Area Health Authority continues to support my work, despite financial problems. I am indebted to all these and to others not mentioned.

This paper is dedicated to the memory of the late Sister Dallas Walker, who contributed so much to my work but tragically died when so young.

\section{References}

1 Bardhan KD. Cimetidine in duodenal ulceration. In: Wastell C, Lance P, eds. Cimetidine. The Westminster Hospital Symposium. Edinburgh, London and New York: Churchill Livingstone, 1978:31-56.

2 Burland WL, Hawkins BW, Horton RJ, Beresford J. The longer-term treatment of duodenal ulcer with cimetidine. In: Wastell C, Lance P, eds. Cimetidine. The Westminster Hospital Symposium. Edinburgh, London and New York: Churchill Livingstone, 1978: 66-78.

3 Bardhan KD, Saul DM, Edward JL, et al. Double-blind comparison of cimetidine and placebo in the maintenance of healing of chronic duodenal ulceration. Gut 1979;20:158-62.

Hansky J, Korman MG. Long-term cimetidine in duodenal ulcer disease. Digestive Diseases and Sciences 1979;24:465-70.

5 Berstad A, Aadland E, Carlsen E, Myren J, Semb LS, Kruse-Jensen A. Maintenance treatment of duodenal ulcer patients with a single bedtime dose of cimetidine. Scand $\mathcal{F}$ Gastroenterol 1979;14:827-31.

- Gudmand-Hoyer E, Jensen KB, Krag E, et al. Prophylactic effect of cimetidine in duodenal ulcer disease. $B r$ Med $₹$ 1978;i:1095-7.

7 Dronfield MW, Batchelor AJ, Larkworthy W, Langman MJS. Controlled trial of maintenance cimetidine treatment in healed duodenal ulcer: short and long-term effects. Gut 1979;20:526-30.

${ }^{8}$ Monthly Index of Medical Specialities (MIMS). $1980 ; 22:(4): 45$.

(Accepted 28 April 1980)

\title{
Obstetric epidural analgesia and postural hypotension
}

\author{
E MOSS, R MACDONALD
}

\section{Summary and conclusions}

Supine and erect arterial pressures were measured daily for six to seven days after delivery in 100 patients, of whom 50 had received epidural analgesia. There was no difference in the magnitude of postural hypotension between the epidural and control groups on any day after delivery, although in both groups the hypotension was greater during the first two days due almost entirely to changes in systolic arterial pressure. The incidence of dizziness on standing was similar in both groups $(9 \%)$.

Thus postural hypotension is no more common in women who have received epidural analgesia than in others. All patients should be helped out of bed after delivery, and any patient who experiences dizziness should have her blood pressure measured until the dizziness disappears.

St James's University Hospital, Maternity Unit, Leeds LS9 TTF

E MOSS, MB, FFARCS, senior registrar in anaesthetics (present appointment: consultant anaesthetist, General Infirmary, Leeds)

R MACDONALD, PHD, FFARCS, consultant anaesthetist

\section{Introduction}

Briggs et $a^{1}$ reported a case of persistent severe postural hypotension after lumbar epidural analgesia during labour in a 26-year-old woman. They attributed this hypotension, which was still present three months after she received the analgesia, to an idiosyncratic reaction to bupivacaine causing a prolonged sympathetic block. To establish whether this case was just an exaggeration of a normal finding or was unique we undertook a study to determine the incidence of postural hypotension in the first week after delivery in patients who had received epidural analgesia for pain relief in labour.

\section{Patients and methods}

We studied 100 patients, of whom 50 received continuous lumbar epidural analgesia during labour (epidural group); the remaining $\mathbf{5 0}$ received pethidine or nitrous oxide, or both, if they required analgesia (control group). Only patients booked for a 10-day stay in hospital were included in the study. No patient lost more than $200 \mathrm{ml}$ of blood. Patients in the control group were chosen to match as closely as possible the age, parity, duration of labour, and date of delivery of patients in the epidural group.

Arterial pressure was measured daily until discharge in each 